\title{
Análisis sobre la planeación financiera de los estudiantes de la Lic. en Administración, Córdoba, España
}

\author{
Analysis on the Financial Planning of Students of the Degree in \\ Administration, Cordoba, Spain
}

\section{Análise sobre o planejamento financeiro dos estudantes de Licenciatura em Administração, Córdoba, Espanha}

\author{
Nadia Natasha Reus González \\ Universidad de Guadalajara, Centro Universitario de los Altos, México \\ nreus@cualtos.udg.mx \\ https://orcid.org/0000-0002-5715-6431
}

\section{Resumen}

Para lograr una mejor situación financiera en los estudiantes de la Universidad Loyola Andalucía, específicamente del Campus de Córdoba, España, es importante tener en cuenta los gastos que implica cursar una licenciatura, en este caso en Administración. Se aplicó un instrumento de medición de 21 ítems sobre gastos, egresos, ahorro, presupuesto y control de gastos para estudiantes inscritos en la universidad y en la carrera en cuestión durante el calendario 2015-B. El trabajo de investigación mostró las variables y resultados. El estudiante, de manera empírica, lleva a cabo la administración respecto de su economía, basada en sus ingresos, los cuales no necesariamente provienen de una fuente propia de trabajo. Finalmente, se analizó cómo administra y cuáles son las estrategias de planeación financiera que lleva a cabo.

Palabras clave: finanzas, planeación financiera, proceso. 


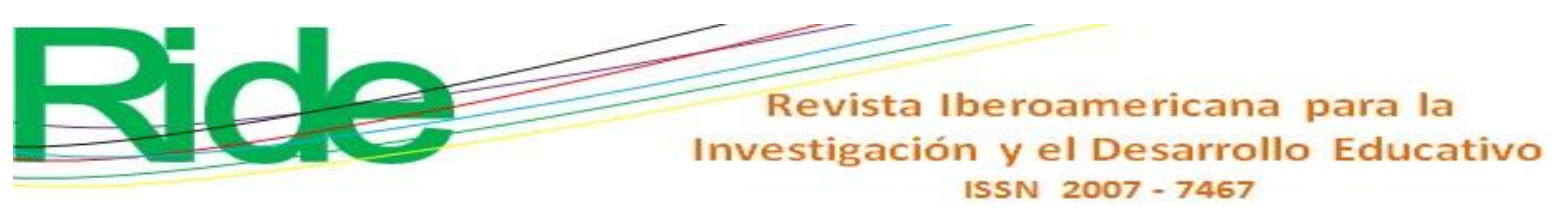

\section{Abstract}

In order to achieve a better financial situation for the students of the Universidad Loyola Andalucía, specifically the Campus of Córdoba, Spain, it is important to take into account the expenses involved in pursuing a bachelor's degree, in this case in Administration. A 21item measurement instrument was applied on expenses, expenses, savings, budget and expense control for students enrolled in the university during the 2015-B calendar. The research work showed the variables and results. The student, empirically, carries out the administration regarding his own economy, based on his income, which does not necessarily come from his own source of work. Finally, it was analyzed how it manages and what are the financial planning strategies it carries out.

Keywords: finance, financial planning, process.

\section{Resumo}

Para alcançar uma melhor situação financeira para os estudantes da Universidade Loyola Andalucía, especificamente o campus de Córdoba, na Espanha, é importante levar em conta as despesas envolvidas na obtenção de um diploma de bacharel, neste caso em Administração. Um instrumento de medição de 21 itens foi aplicado às despesas, despesas, poupança, orçamento e controle de despesas dos estudantes matriculados na universidade e na carreira em questão durante o calendário 2015-B. O trabalho de pesquisa mostrou as variáveis e resultados. O aluno, empiricamente, realiza a administração de sua economia, com base em sua renda, que não necessariamente vem de sua própria fonte de trabalho. Por fim, analisou-se como administra e quais são as estratégias de planejamento financeiro que realiza.

Palavras-chave: finanças, planejamento financeiro, processo.

Fecha Recepción: Diciembre 2019

Fecha Aceptación: Mayo 2020 


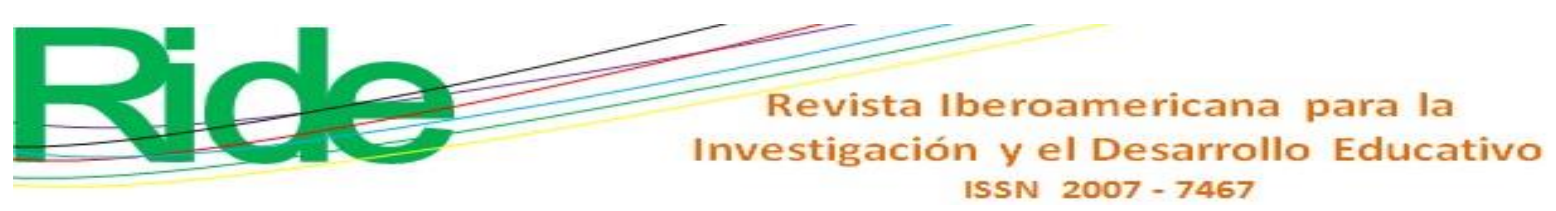

\section{Introducción}

La familia moderna debe funcionar como el equivalente de la administración de una empresa, una forma de relacionarse que permita dialogar la toma de decisiones importantes y, aunque alguien tenga la resolución final, ayude a que todos se involucren y entiendan por qué se hacen las cosas y la adquisición de ciertos hábitos.

El aprendizaje es una de las herramientas más importantes para tener una comunicación efectiva en los temas financieros. Va más allá de que los padres siempre manejen y tomen las finanzas de un hogar; por el contrario, se debe evitar repetir los mismos errores en los que se puede caer. También está el hecho de que en una familia joven se pueden discutir los conceptos básicos financieros y en algunos casos es positivo aceptar la ignorancia como primer paso para la investigación y el análisis de una administración financiera (Tovar, 12 de mayo de 2016).

Por ello, es aconsejable debatir sobre los principios básicos en la familia y hablar sobre el ahorro, el presupuesto, gastos, ingresos, etc. La educación financiera básica y la administración de los recursos con los que se cuenta se inician en el seno familiar y lo más valioso es el ejemplo que ponen los padres con sus hijos.

Toda familia tiene la responsabilidad de proveer los elementos básicos para satisfacer sus propias necesidades, claro, hasta donde le sea posible. La responsabilidad de administrar la economía familiar debe iniciar en la pareja, con una actitud de confianza y franqueza.

La educación financiera a edad temprana es de suma importancia. Se debe dar en el seno familiar y su formación debe iniciar entre los 9 y los 12 años de edad, ya que se considera que a partir de ese rango pueden ser personas responsables. La finalidad es que su aprendizaje sobre planificación financiera les ayuda a aprovechar de mejor manera su dinero. Se trata de algo tan importante como escribir o leer (Marloreley, 5 de abril de 2016).

Ahorrar a partir de los ingresos, para algunas personas, puede llegar a ser complicado, mas no imposible. Es significativo hacerse del hábito para quien no lo tiene, ya que es benéfico para cualquier economía, sobre todo la personal y aún más para los alumnos y los hogares.

Administrar sabiamente el dinero puede proporcionar seguridad y promover el bienestar de la familia. Los miembros pueden experimentar problemas financieros debido al desempleo, por gastar en exceso, a raíz de emergencias inesperadas o al mal manejo y administración de las finanzas. 


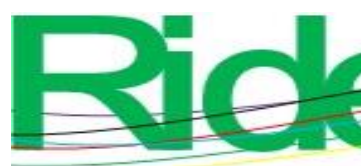

Revista Iberoamericana para la Investigación y el Desarrollo Educativo ISSN $2007-7467$

Es ahí cuando los padres de familia o tutores deben transmitir o concientizar sobre la importancia del manejo y administración del dinero a sus hijos desde temprana edad, de tal manera que vayan adquiriendo una cultura financiera sana para en que en el futuro tengan una buena calidad de vida y una economía estable.

Llevar un registro de sus gastos, anotar y evaluar sus ingresos y gastos mensuales, así como determinar la manera de reducir los gastos no esenciales, son algunas de las técnicas a las que una familia puede recurrir para alcanzar una economía estable.

La administración financiera permite lograr un mayor bienestar cuando las familias tienen nociones básicas sobre lo que significa ser sanos financieramente. Las autoridades financieras se han enfocado en promoverla, pero es necesario dedicar mayores esfuerzos para lograr un aumento de la educación en este rubro en el grueso de la población.

De acuerdo con Villagómez (2014), las personas deben buscar mantener su economía estable a lo largo de su vida y lograr obtener un hábito de planeación financiera en sus gastos personales para no tener ningún problema económico.

Herrera y Raccanello (2014), por su parte, mencionan que, con base en la experiencia, la administración financiera puede traer beneficios a los individuos cuando se acompaña del desarrollo de la educación financiera; de otra forma, puede fomentar un uso poco eficiente para la población que la obtiene.

En pocas palabras, la administración financiera se encarga de planear, controlar, organizar y dirigir los recursos económicos dentro de la familia, al mismo tiempo, permite vislumbrar las decisiones que ofrecen mejores beneficios y que implican un menor riesgo (Riquelme, 14 de julio de 2015).

Planear financieramente permite analizar los movimientos monetarios del individuo, un hogar o la propia empresa haciendo fructífera su economía (Olmedo, 2009). Las finanzas aplican en cualquier institución y mercado financiero, así como en las micro y grandes empresas (Ochoa y Saldívar, 2012).

Dentro de la planeación se constituyen objetivos factibles de alcanzar a través de las diferentes estrategias, que al realizarse de forma metódica garantizan un proceso seguro (Morales y Morales, 2010).

La planeación financiera se aplica tanto en la vida empresarial como en lo personal. Correa, Ramírez y Castaño (2010) indican que la planeación financiera es una herramienta que se utiliza en las empresas o negocios que visualizan el plan empresarial de forma 


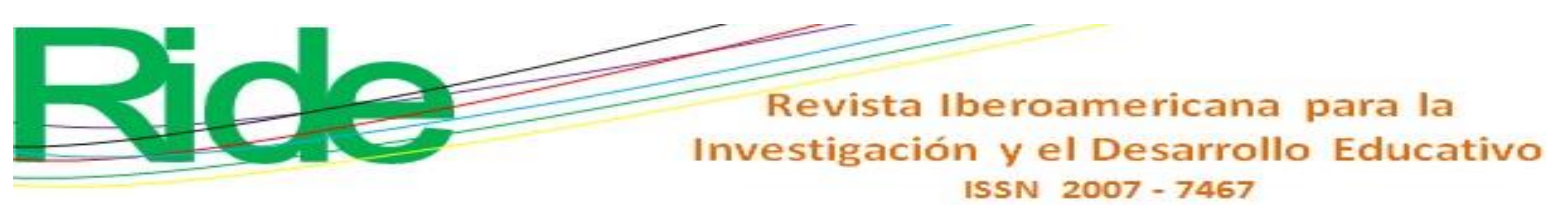

generalizada, considerando diferentes contextos, por lo que esta idea se puede concretizar en el plano individualizado.

\section{Justificación}

Hoy en día la exigencia en varios aspectos de nuestra vida es muy alta, máxime los de carácter financiero. Hay una señalada preocupación por la administración financiera: cómo realizar de manera adecuada desde un presupuesto hasta sumar ahorro, ingresos, egresos, deudas, etc.

Cuando no se tiene claridad de los conceptos básicos financieros, aunado a no llevar a cabo una planeación adecuada de los ingresos y egresos, se pueden contraer endeudamientos, así como no ser capaz de planear situaciones económicas a futuro y, por consecuencia, no organizar de forma pertinente el ahorro o hasta no generarlo (Núñez, 2013).

El estrés financiero, según la Comisión Nacional para la Protección y Defensa de los Usuarios de Servicios Financieros [Condusef] (30 de agosto de 2019), es cuando se genera ansiedad o tensión persistente en los empleados. Este estrés también se puede extrapolar al ámbito educativo, donde es muy difícil, por no decir imposible, alcanzar el aprovechamiento académico si se tienen problemas económicos.

Una recomendación importante es considerar la elaboración de un presupuesto de ingresos como de egresos. Para los gastos se consideran dos variables importantes: el gasto necesario y el gasto por gusto; mientras que para el ahorro está la variable de corto y la de largo plazo (Condusef, 3 de junio de 2019).

El ahorro implica un esfuerzo periódico para alcanzar metas y objetivo fijados previamente con un orden en las fianzas personales y no incrementar deudas.

\section{Objetivo}

Analizar los hábitos de planeación financiera de los estudiantes en la licenciatura en Administración de la Universidad Loyola Andalucía, Campus de Córdoba, en España, al igual que su trayectoria escolar, mediante una encuesta que contiene 21 preguntas. 
Metodología

Se realizó una encuesta como prueba piloto para la validación del instrumento de medición con 21 preguntas generadoras de datos sobre gastos, egresos, ahorro, presupuesto, control de gastos, gastos imprevistos y el rendimiento escolar del estudiante.

El trabajo de campo se realizó con estudiantes inscritos en la licenciatura ya mencionada en el calendario 2015-B. El diseño de la investigación es de tipo descriptivotransversal.

\section{Determinación del tamaño de muestra}

La población del estudio estuvo integrada por los alumnos de la licenciatura en Administración de la Universidad Loyola Andalucía con estatus activo durante el ciclo 2015B, por lo que se realizó un total de 219 encuestas.

\section{Resultados}

Figura 1. Obtención de ingresos

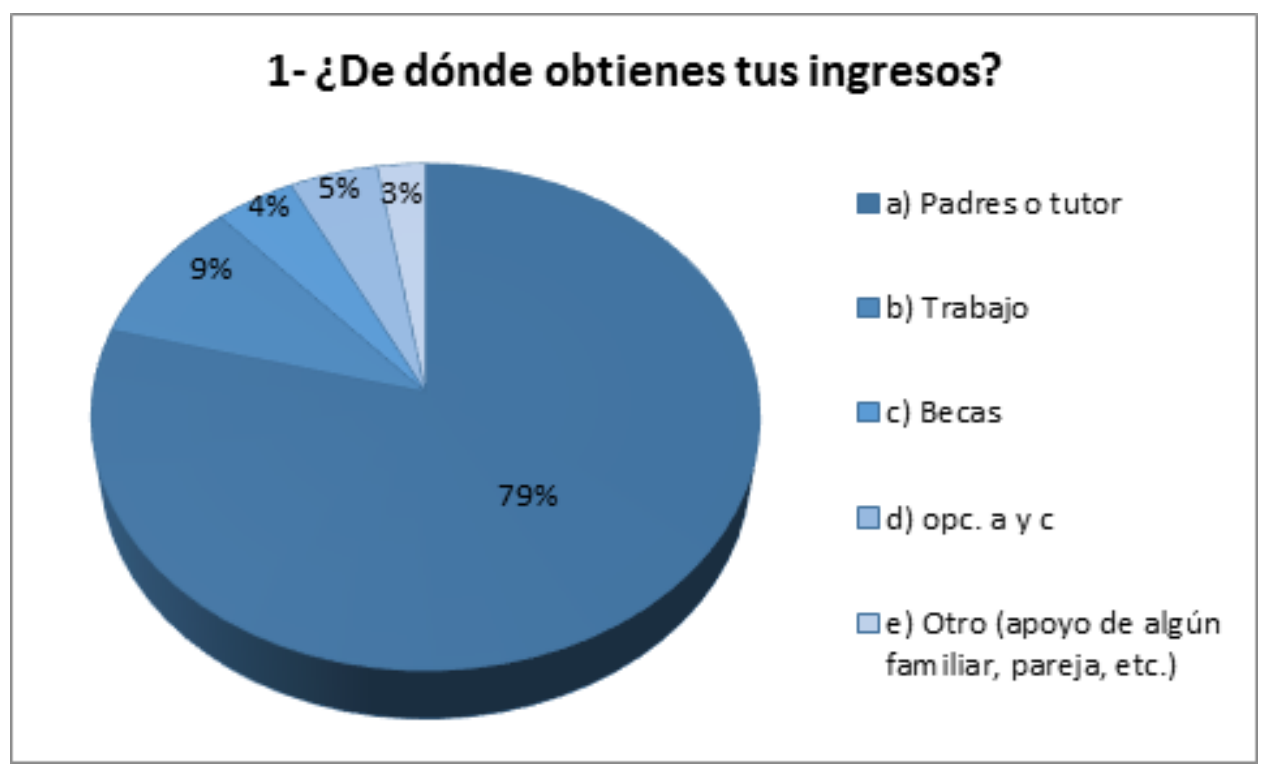

Fuente: Elaboración propia

En la figura 1 se observa que una gran mayoría de los estudiantes de la licenciatura en Administración obtiene sus ingresos vía sus padres o tutores, a saber: 79 \% de la muestra; mientras que tan solo $3 \%$ obtiene sus ingresos por medio de otras instancias: como su pareja, 


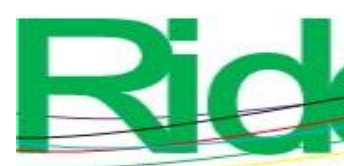

\section{Revista Iberoamericana para la Investigación y el Desarrollo Educativo ISSN $2007-7467$}

apoyo de otro familiar, entre otras. Esto quiere decir que la mayoría de los estudiantes depende de sus padres y no de un trabajo para seguir con sus estudios escolares.

Figura 2. Ingreso mensual

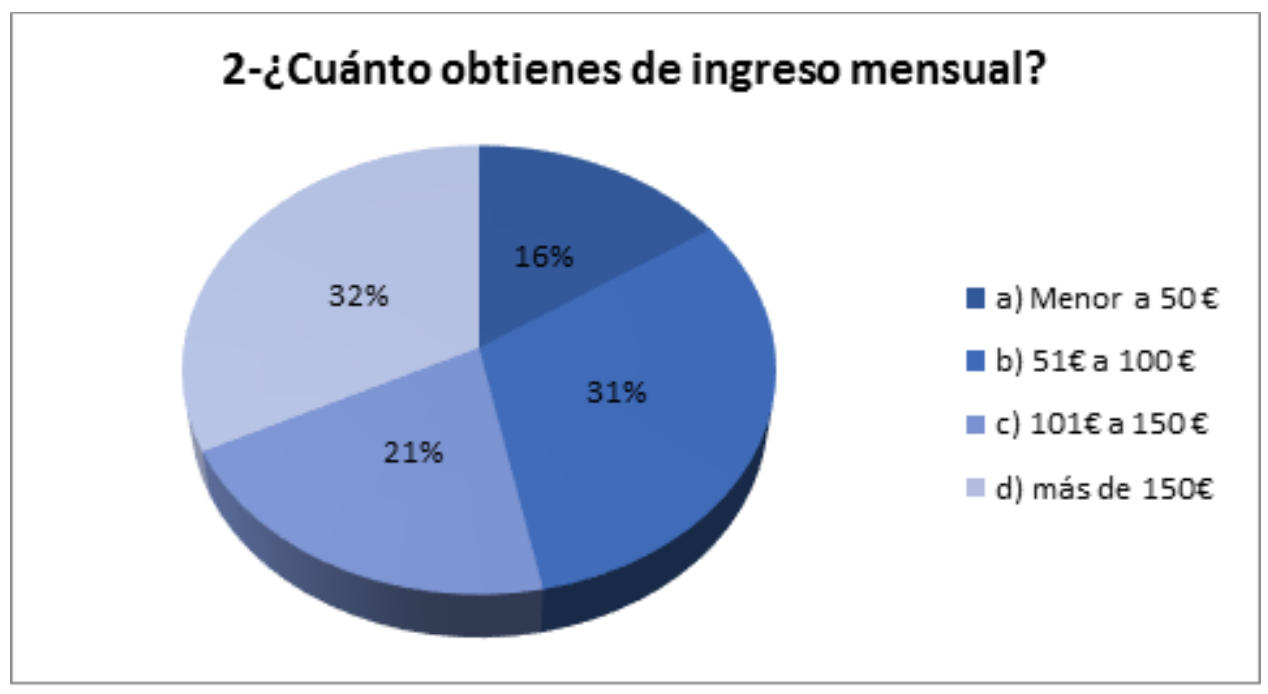

Fuente: Elaboración propia

Se puede notar en la figura 2 que $32 \%$ de los encuestados tiene un ingreso mensual de más de $€ 150$, quienes, en comparación con $16 \%$ de la muestra que registra ingresos menores de $€ 50$ al mes para solventar todas sus necesidades escolares, de ocio, entre otras, cuentan con un mejor estilo de vida.

Figura 3. Gastos semestrales

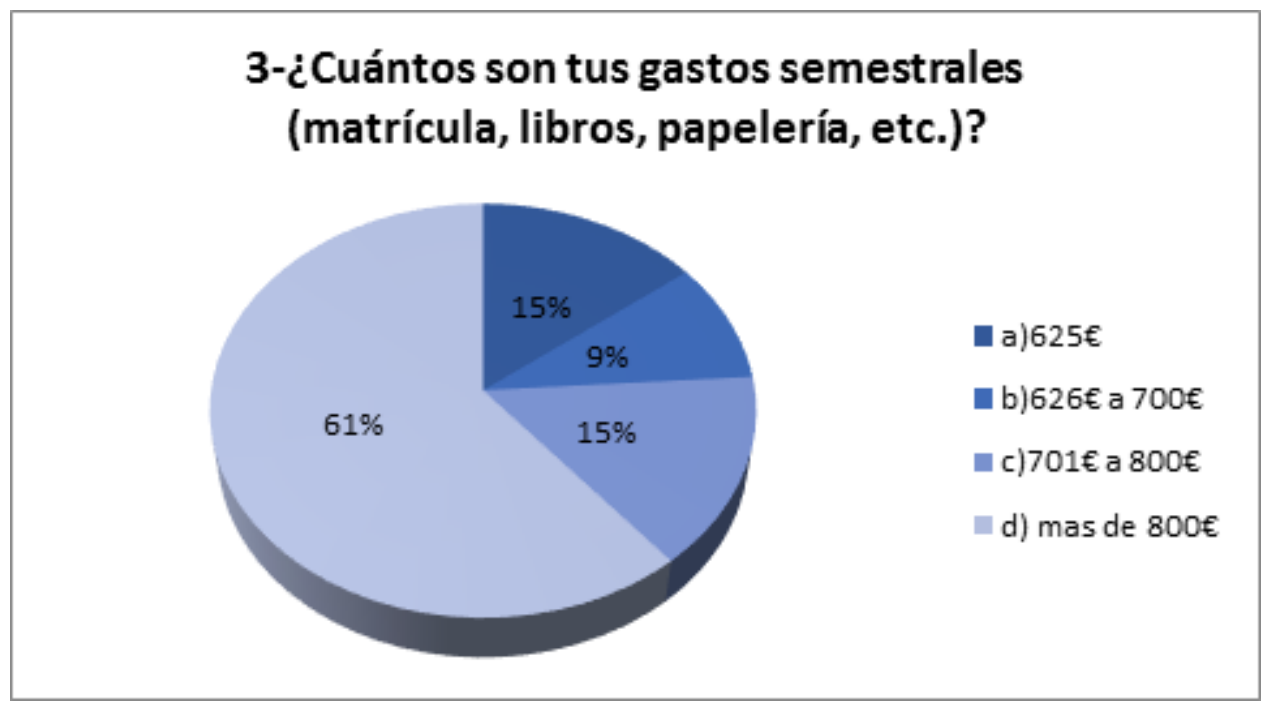

Fuente: Elaboración propia 


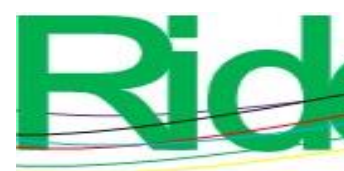

Revista Iberoamericana para la
Investigación y el Desarrollo Educativo
ISSN $2007-7467$

En la figura 3 observamos los gastos semestrales que tienen los alumnos: $61 \%$ calcula sus gastos en más de $€ 800,15 \%$ de $€ 701$ a $€ 800$ y otro $15 \%$ considera que bastan $€ 625$ al mes para poder cubrir sus gastos escolares: desde la matrícula, útiles escolares, tecnología, libros, etc.

Figura 4. Gastos en materiales escolares

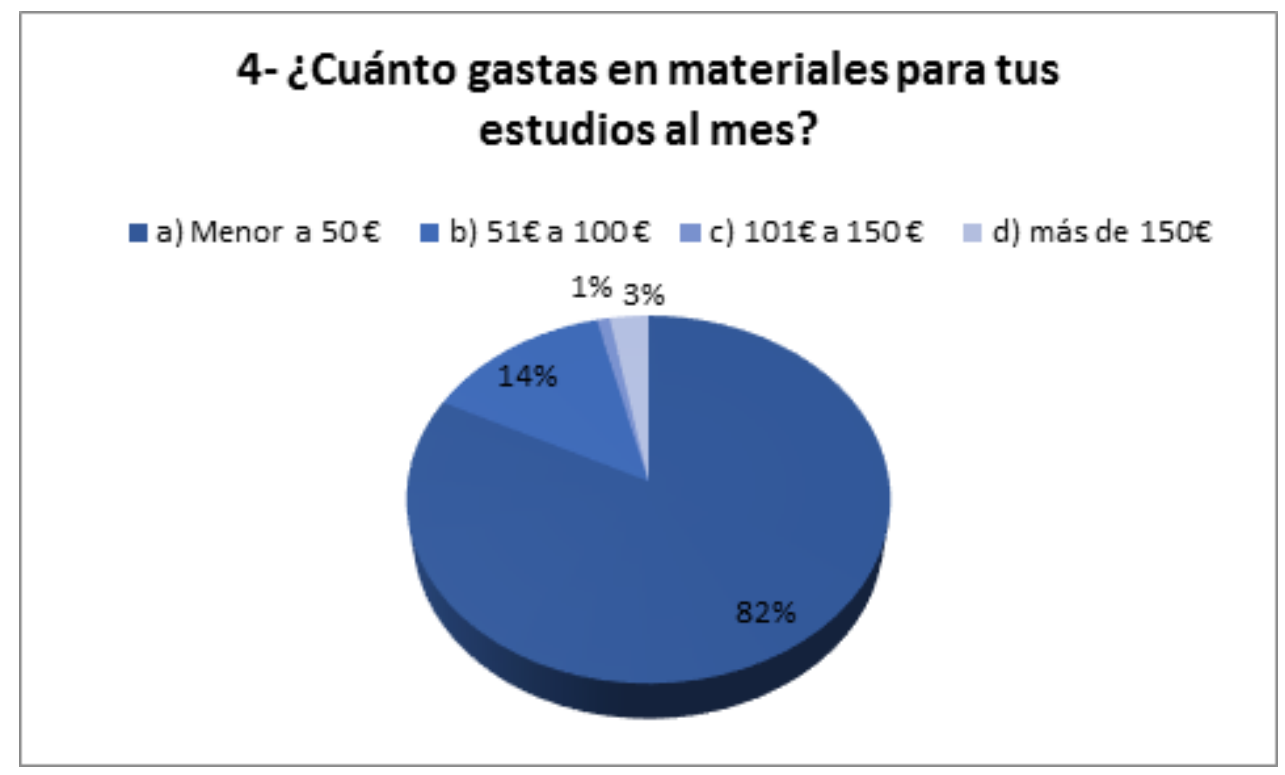

Fuente: Elaboración propia

Asimismo en la figura 4, $82 \%$ de los estudiantes gasta menos de $€ 50$ en materiales escolares al mes, mientras que $14 \%$ gasta de $€ 51$ a $€ 100$ y $3 \%$ solo gasta más de $€ 150$, como se muestra en la figura 4. 


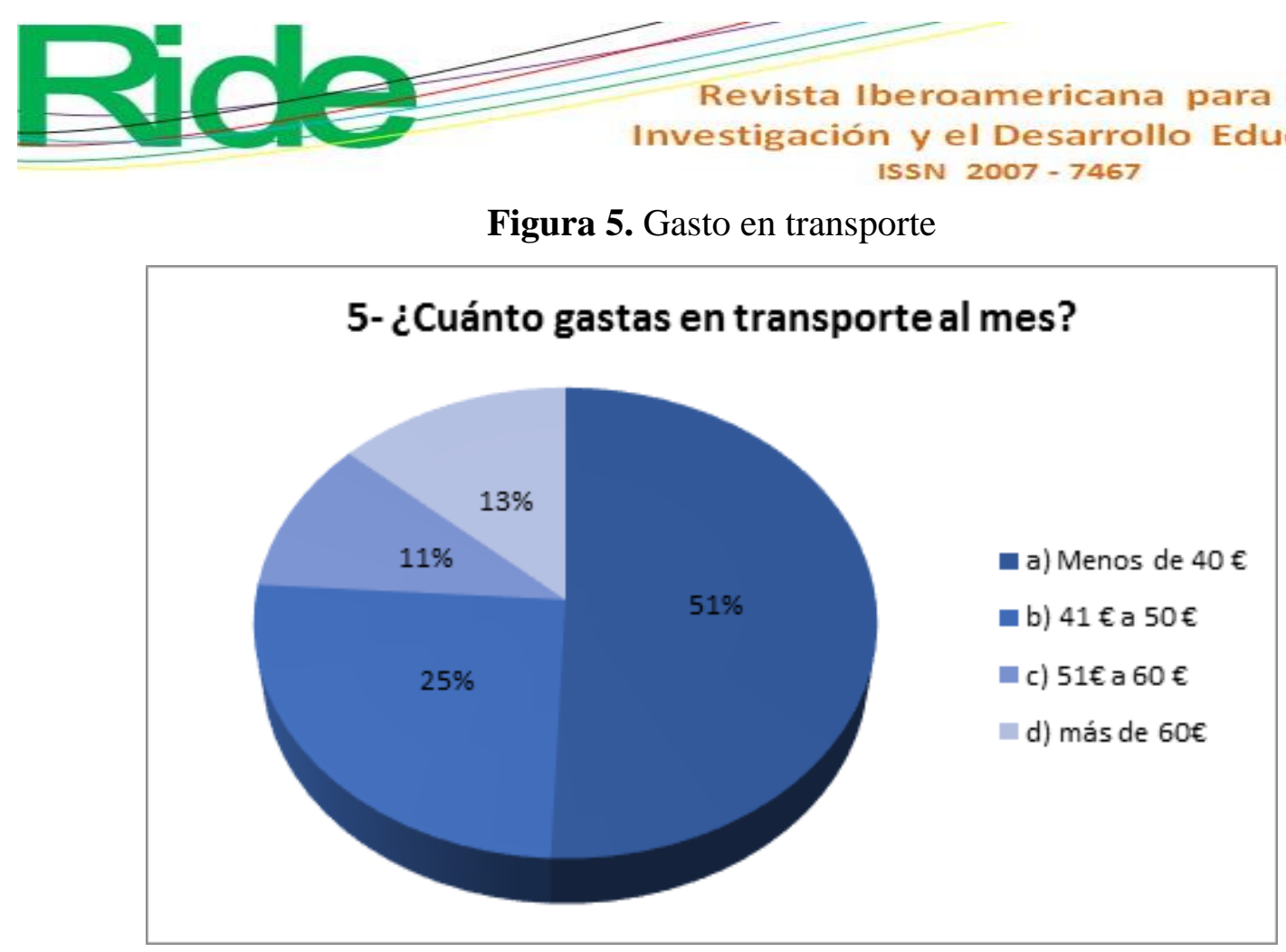

Fuente: Elaboración propia

La figura 5 muestra que $51 \%$ de los estudiantes gasta en transporte menos de $€ 40$, $25 \%$ gasta de $€ 41$ a $€ 50$, en tanto que $11 \%$ gasta de $€ 51$ a $€ 60$ y $13 \%$ gasta más de $€ 60$. Esto quiere decir que la mayoría de los estudiantes no cuenta con auto propio y tiende a tomar el bus u otras alternativas para llegar a sus destinos.

Figura 6. Gasto de alimentación fuera del hogar

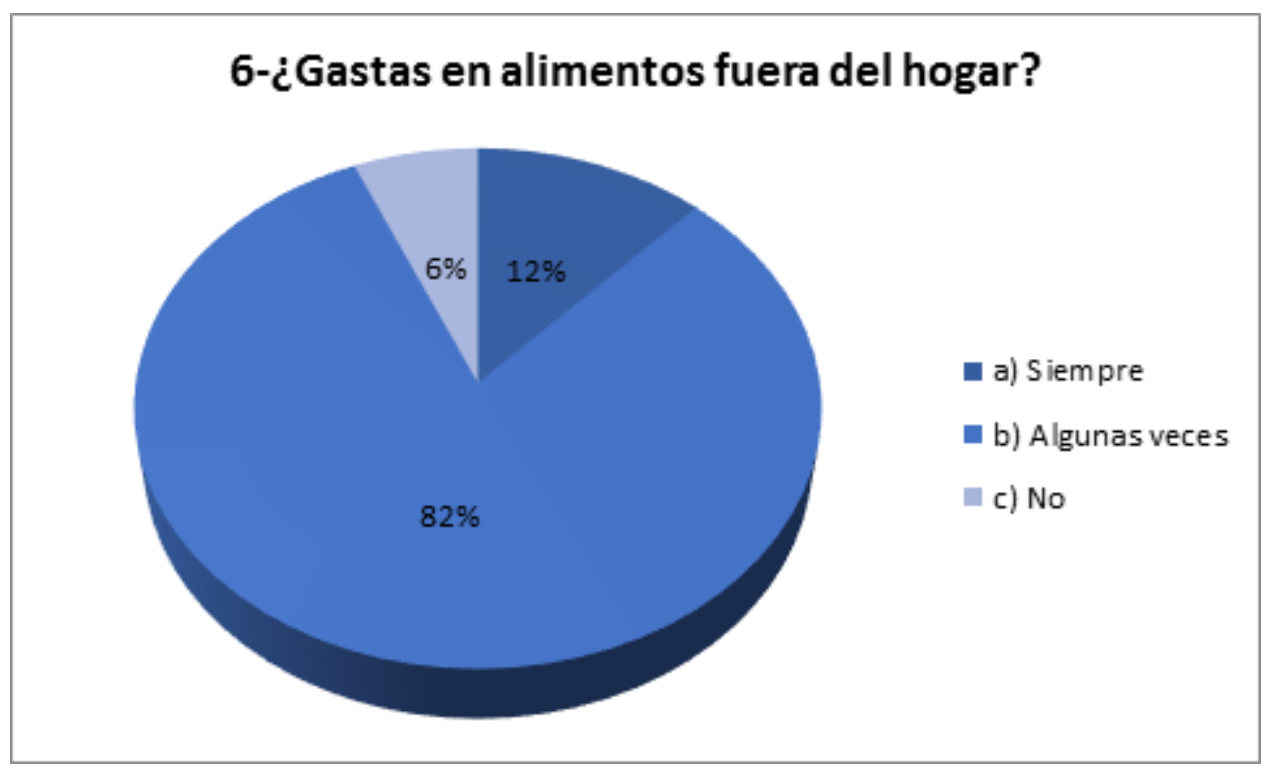

Fuente: Elaboración propia 


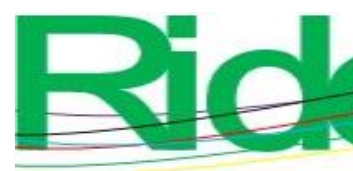

Revista Iberoamericana para la
Investigación y el Desarrollo Educativo
ISSN $2007-7467$

Respecto al gasto en alimentos fuera del hogar, como se muestra en la figura $6,12 \%$ de los alumnos algunas veces tiene la necesidad de recurrir a este gasto, $82 \%$ siempre gasta fuera del hogar y solo $6 \%$ de ellos no genera gastos por este concepto. La universidad tiene su propia cafetería y es mucho más fácil para los alumnos poder alimentarse allí y no perder su tiempo en trasladarse.

Figura 7. Gasto en alimentos fuera del hogar al mes

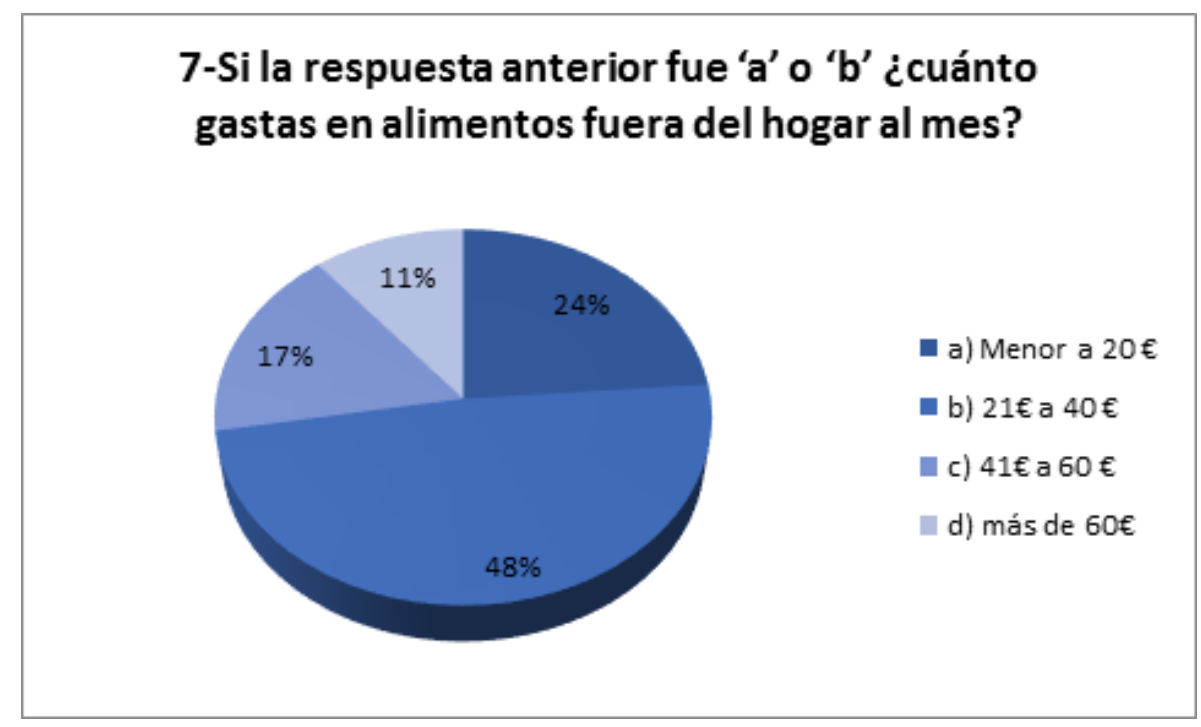

Fuente: Elaboración propia

Las cantidades que se reflejan en la figura 7 respecto a los gastos en alimentos son las siguientes: $24 \%$ de los estudiantes respondieron que su gasto mensual es por menos de $€ 20,48 \%$ manifiesta gastar de $€ 21$ a $€ 40$ mensuales, $17 \%$ de ellos gasta de $€ 41$ a $€ 60$ y solo $11 \%$ gasta más de $€ 60$ al mes. Los alimentos fuera de casa son económicos y accesibles para los estudiantes cuando son requeridos. 


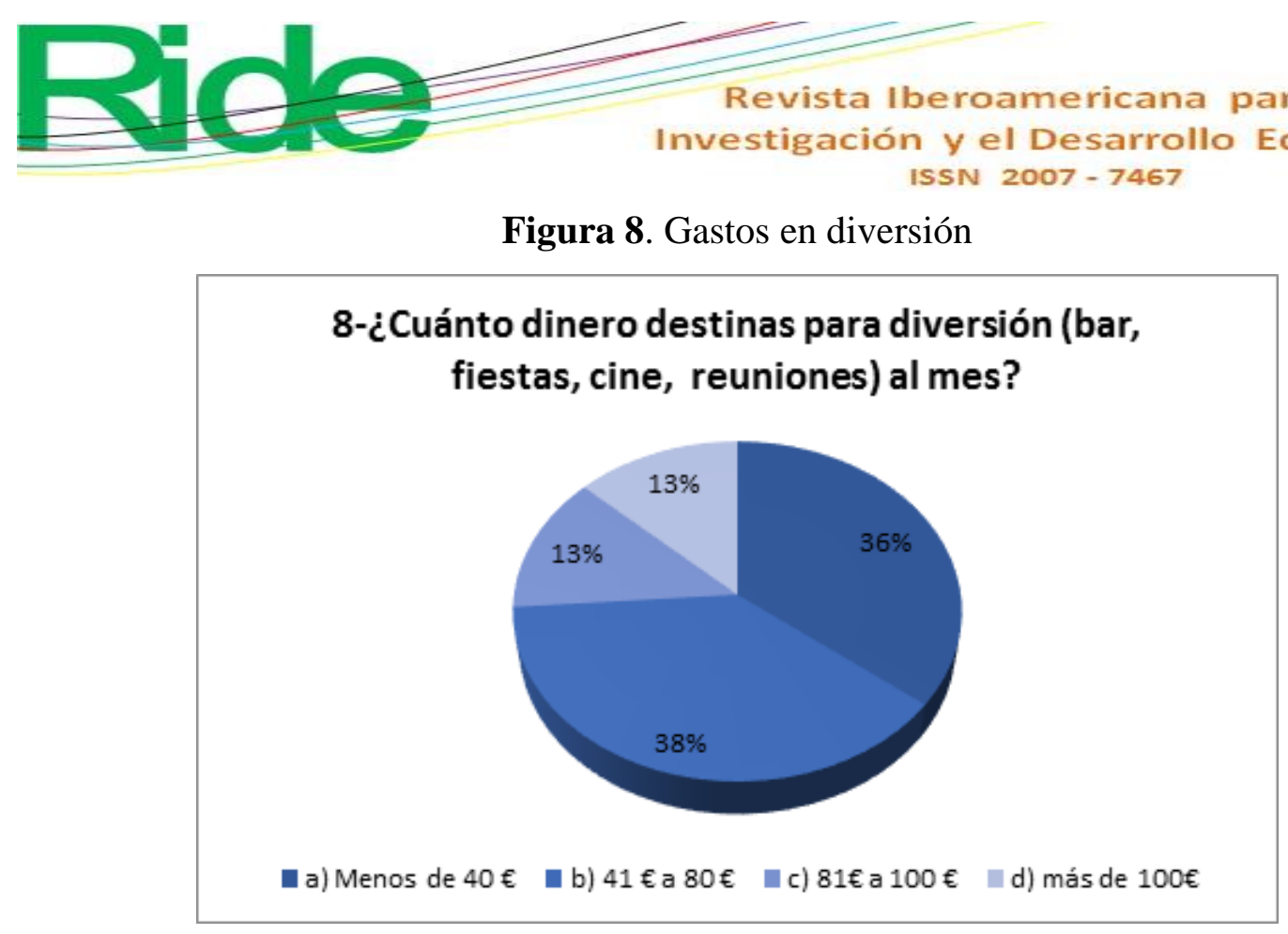

Fuente: Elaboración propia

La figura 8 muestra que $38 \%$ de los estudiantes gasta de $€ 41$ a $€ 80$ para divertirse al mes, $36 \%$ gasta menos de $€ 40,13 \%$ gasta más de $€ 100$ y otro $13 \%$ de $€ 81$ a $€ 100$ por mes. Esto quiere decir, entre otras cosas, que es barato divertirse en Córdoba, España.

Figura 9. Hábito del ahorro

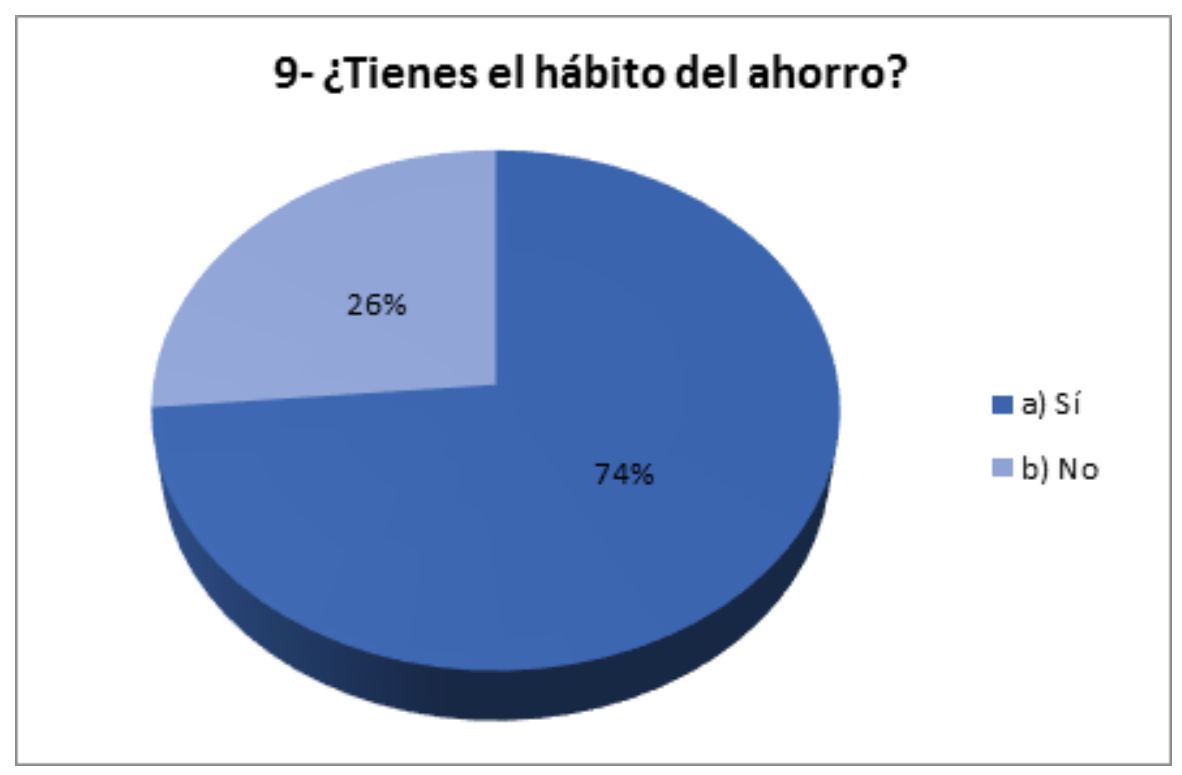

Fuente: Elaboración propia

En cuanto a la forma de ahorro personal, la figura 9 muestra que, la mayoría de los estudiantes de la licenciatura en Administración de la Universidad de Loyola Andalucía tiende a ahorrar (74\%). Esto se debe a que gran parte de ellos pone en práctica sus nociones 


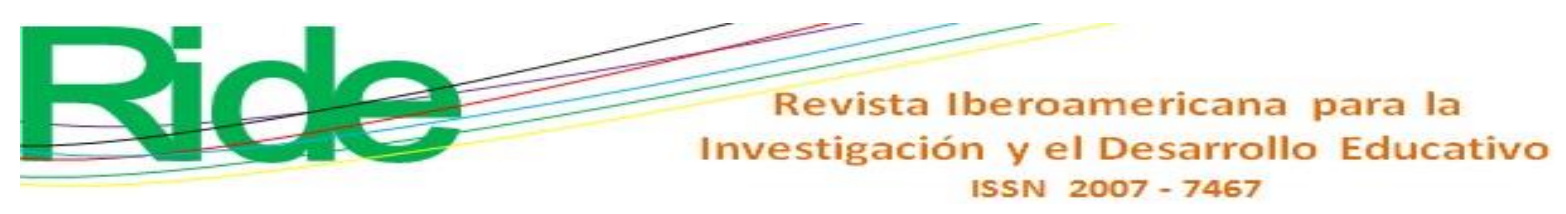

financieras, tal y como estas se reflejan en su plan de estudios, y con ello desarrollan sus habilidades autogestoras.

Figura 10. Ahorro mensual

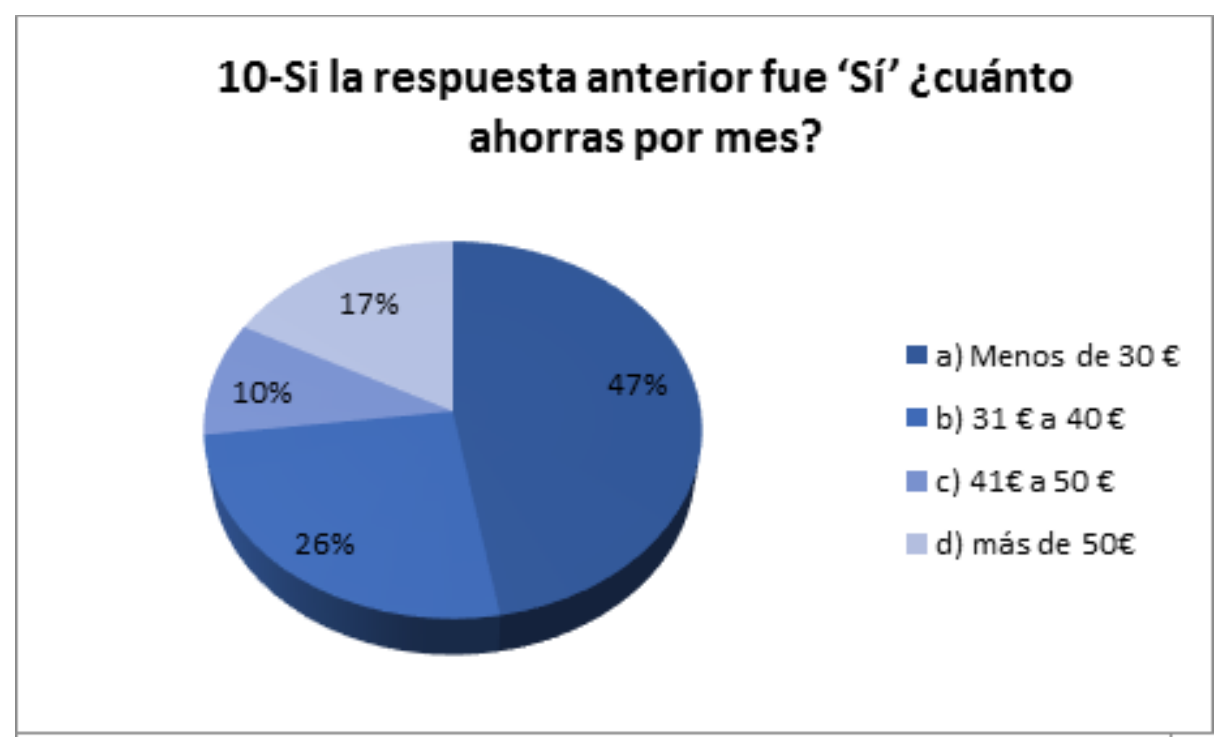

Fuente: Elaboración propia

En la figura 10 se aprecia que $47 \%$ de los estudiantes que tienden a ahorrar ahorra menos de $€ 30$ al mes, $26 \%$ ahorra de $€ 31$ a $€ 40,10 \%$ ahorra de $€ 41$ a $€ 50$ y, por último, $17 \%$ ahorra más de $€ 50$, lo que quiere decir que la mayoría ahorra del dinero que sus padres o tutores les dan, los estudiantes lo administran y así lo puedan gastar en sus necesidades y gustos. 


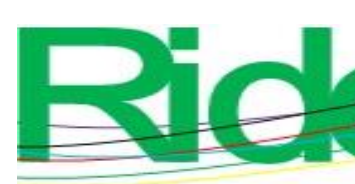

\section{Revista Iberoamericana para la Investigación y el Desarrollo Educativo ISSN $2007-7467$}

Figura 11. Porcentaje del ingreso mensual para el ahorro

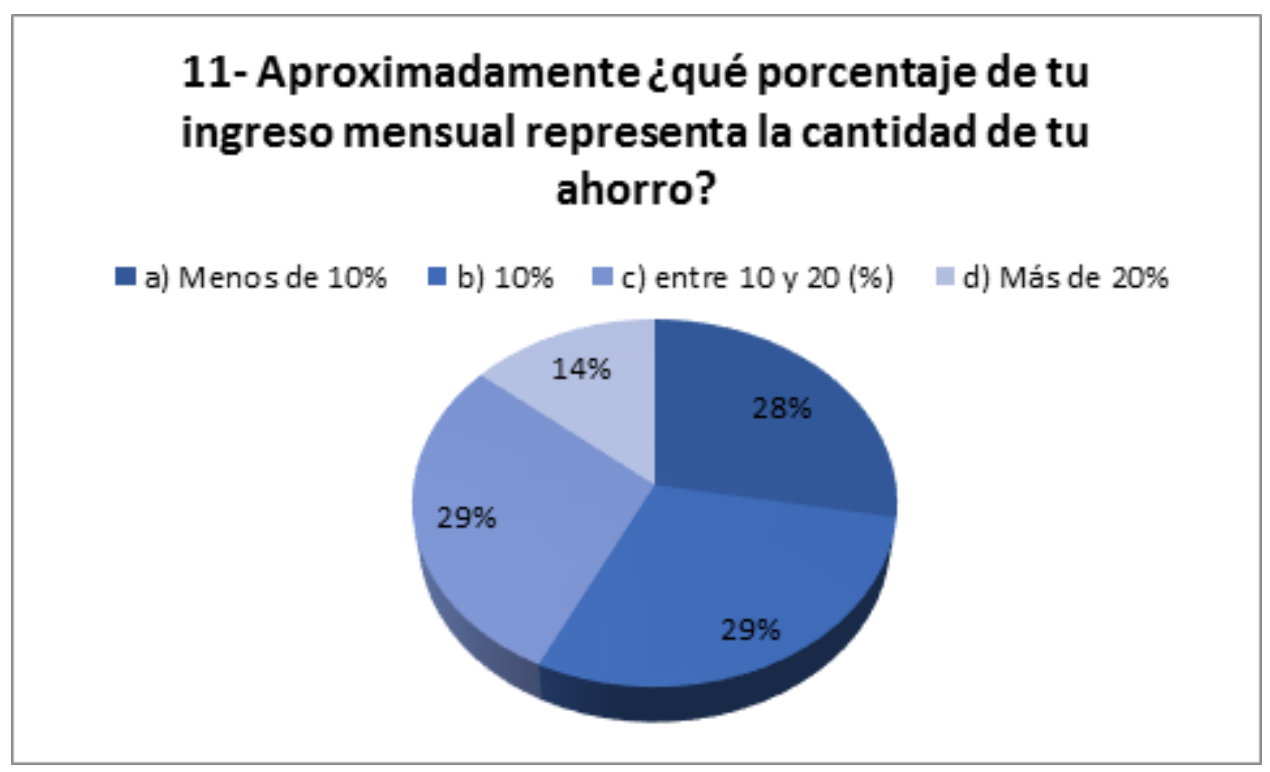

Fuente: Elaboración propia

En la figura 11 se puede mostrar que, del total de estudiantes de la licenciatura en Administración participantes, $28 \%$ ahorra menos de $10 \%$ del total de sus ingresos mensuales, mientras que $29 \%$ de los alumnos ahorra $10 \%$ de los ingresos que reciben y un mismo porcentaje de alumnos, $10 \%$, ahorra entre $10 \%$ y $20 \%$. Esto quiere decir que la mayoría de los estudiantes tienen la cultura del ahorro.

Figura 12. Control de ingresos y gastos

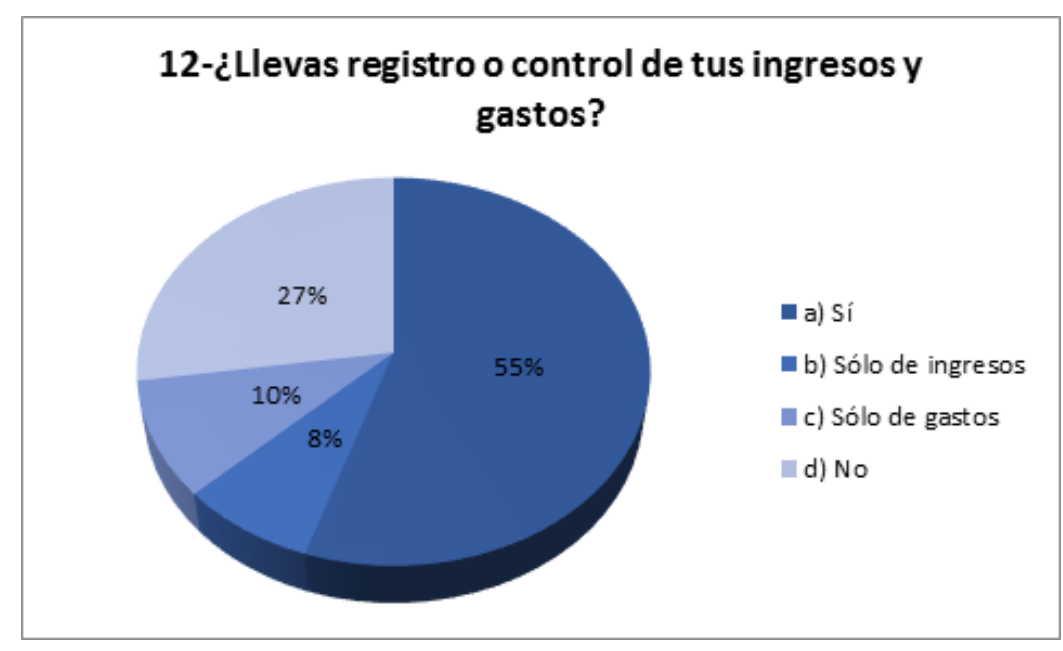

Fuente: Elaboración propia 


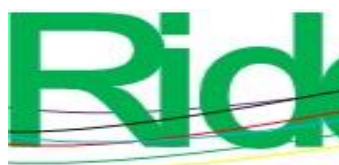

\section{Revista Iberoamericana para la Investigación y el Desarrollo Educativo ISSN $2007-7467$}

Sobre el registro o control de ingresos y gastos, de los 219 estudiantes encuestados, según se muestra en la figura 12, $55 \%$ de ellos sí lleva un registro, o al menos eso contestaron, y solo $27 \%$ respondió no llevar una bitácora o registro de este tipo, lo cual da a entender que gran parte de los alumnos cuentan con una base de datos, ya sea en escrito o en electrónico, sobre sus entradas y salidas financieras. Por extensión, se puede deducir que su cultura financiera es muy buena.

Figura 13. Presupuesto de ingresos y gastos

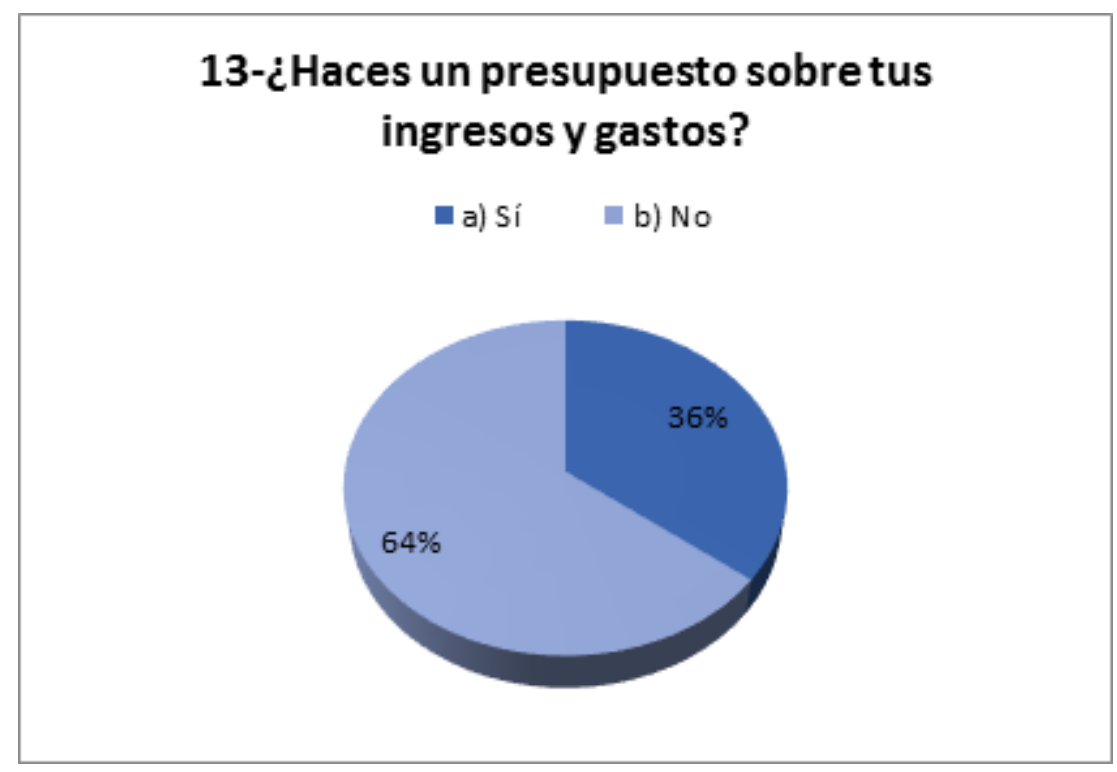

Fuente: Elaboración propia

En la figura 13 se muestra que $64 \%$ de los estudiantes no elabora un presupuesto sobre sus ingresos y gastos, mientras que $36 \%$ de ellos sí lo lleva. Hay que hacer mayor énfasis en este rubro para que un estudiante a futuro pueda solventar sus gastos y evitar el adquirir deudas y, por ende, mejorar su economía y su calidad de vida. 


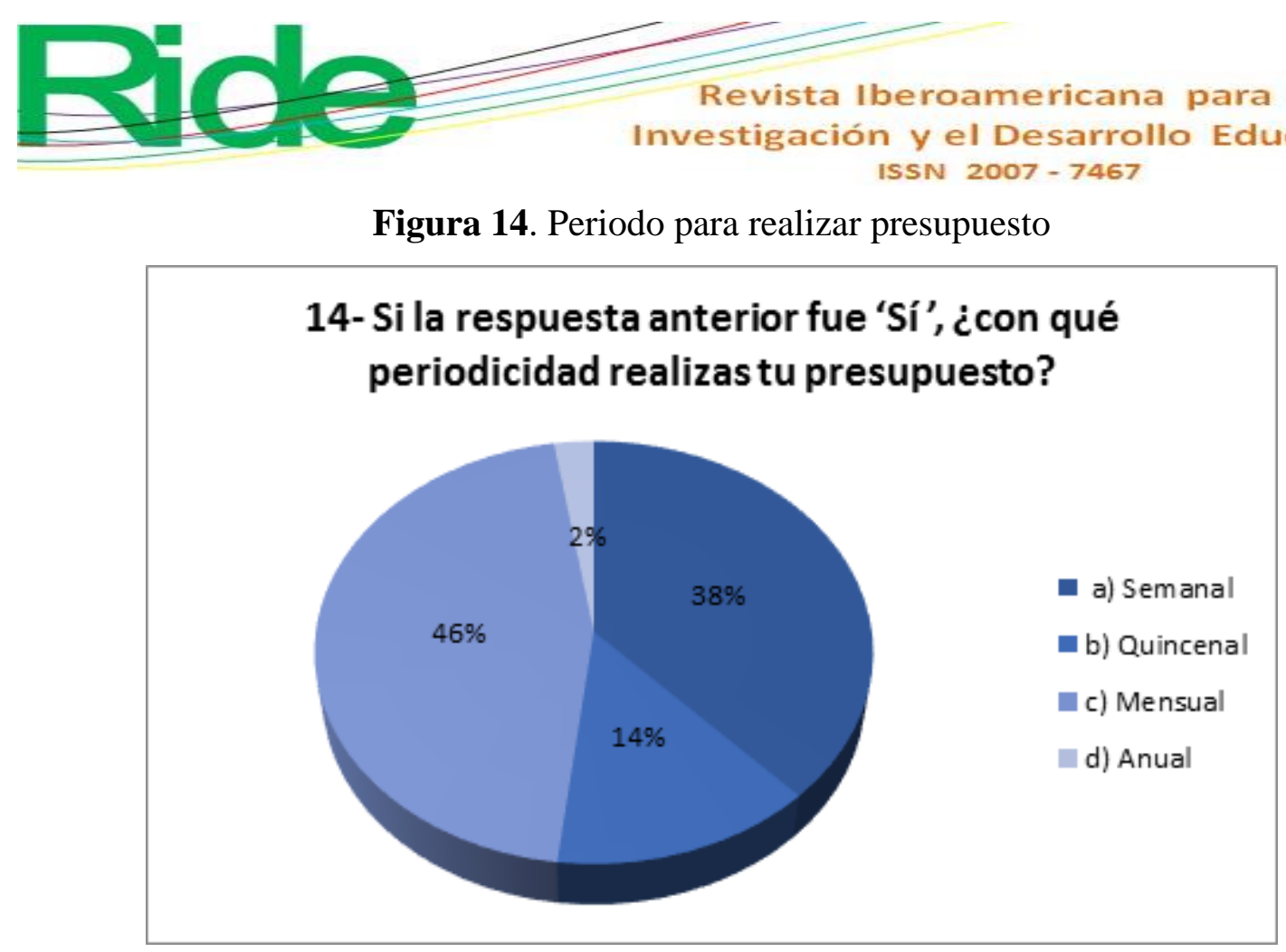

Fuente: Elaboración propia

En la figura 14 se muestra que, de los 219 estudiantes encuestados, 79 de ellos sí realizan un presupuesto sobres sus ingresos y gastos, de los cuales $46 \%$ lo realiza mensualmente, $38 \%$ de ellos lo realiza semanalmente, $14 \%$ quincenal y solo $2 \%$ lo realiza de manera anual. Lo bueno de esto, sin importar el periodo, es que se puede contar con información de un presupuesto para tener una proyección de sus ingresos y gastar en lo que se tiene planeado y así tener un mejor manejo de sus recursos financieros y una mejor administración del dinero a la hora de utilizarlo.

Figura 15. Deudas

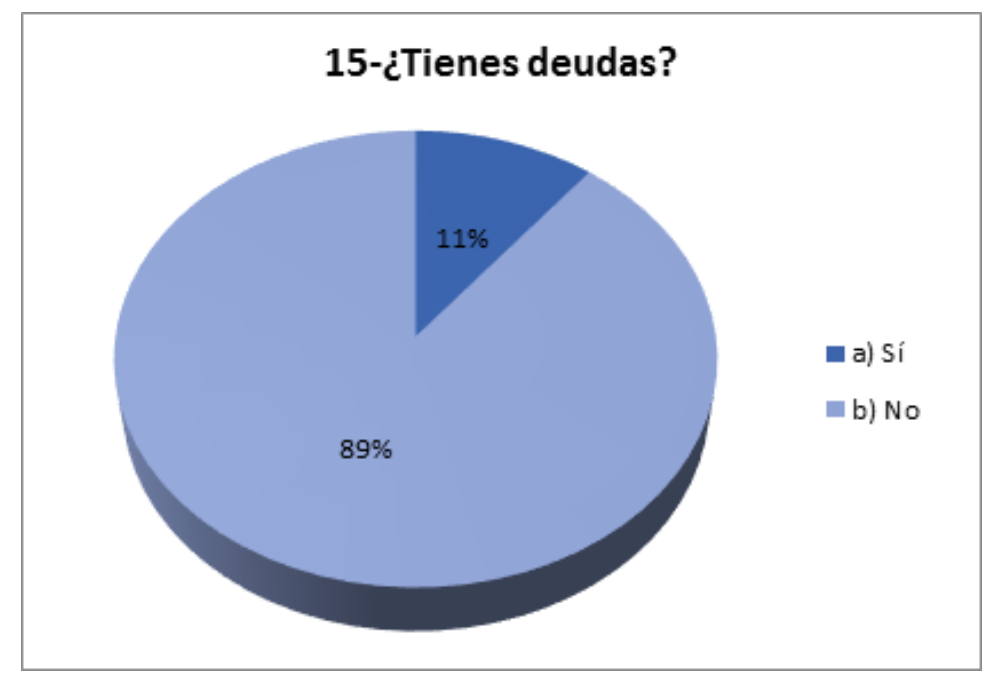

Fuente: Elaboración propia 


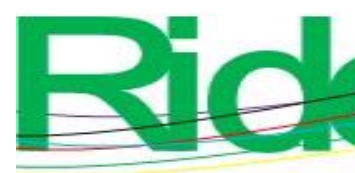

\section{Revista Iberoamericana para la Investigación y el Desarrollo Educativo ISSN $2007-7467$}

En la figura 15 se muestra que, $11 \%$ de los estudiantes, a pesar de estar en la universidad, adquieren deudas por su mal manejo o control de sus ahorros, mientras que $89 \%$ tiende a poseer una cultura del ahorro inclusive con un alto porcentaje, aspecto que demuestra que la administración financiera de forma personal es muy arraigada en gran parte de los estudiantes de la Universidad de Loyola Andalucía.

Figura 16. Pago de deudas

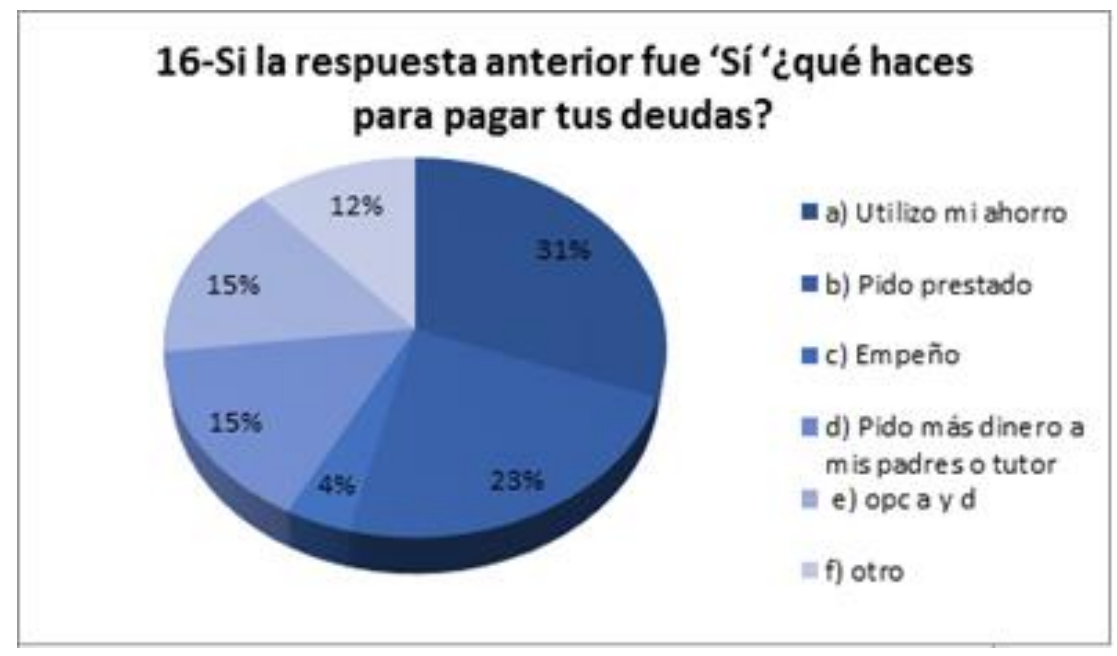

Fuente: Elaboración propia

En la figura 16 se muestra que, de los 219 estudiantes encuestados, solo 24 de ellos tienen deudas, de los cuales $31 \%$ utiliza su ahorro para solventarlas, $23 \%$ tiene que pedir prestado, $4 \%$ empeña algo de valor para pagar, $15 \%$ pide dinero a sus padres o tutor como última alternativa y también utiliza sus ahorros y $12 \%$ no considera ninguna de las opciones sugeridas, sin especificar la forma a la que recurre para solventar sus deudas. 


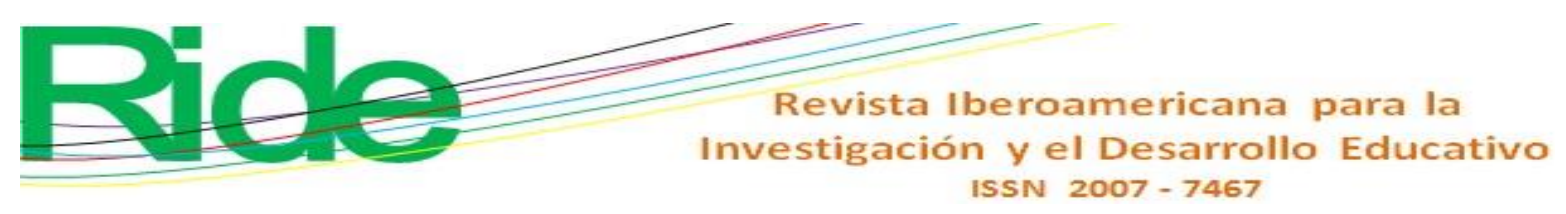

Figura 17. Residente en Córdoba

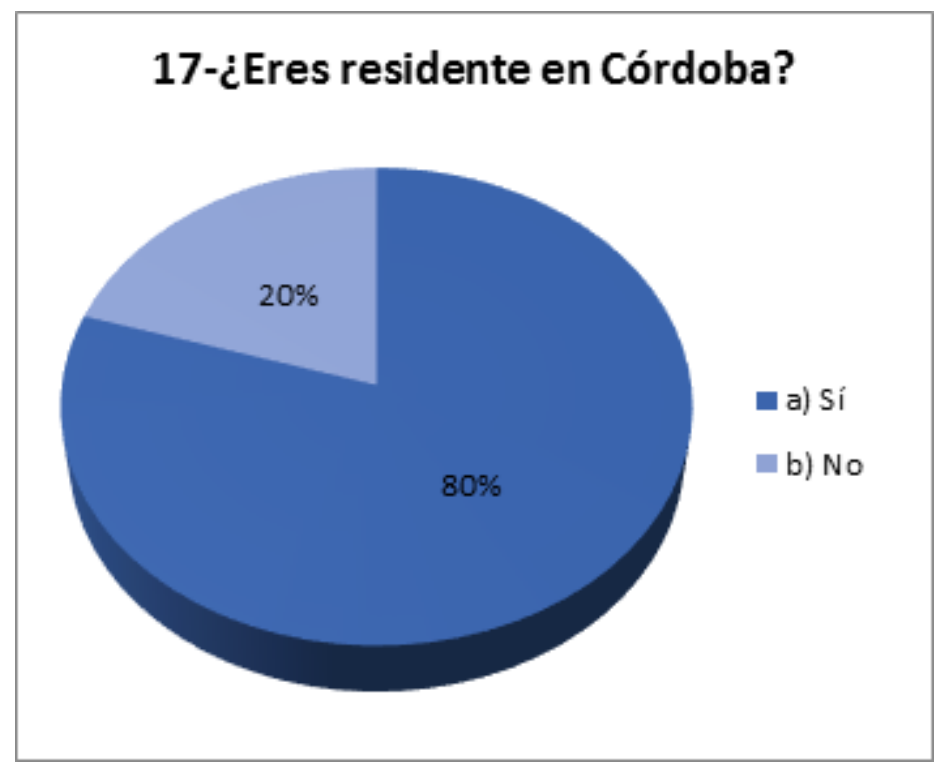

Fuente: Elaboración propia

En la figura 17 se muestra que, $80 \%$ de los estudiantes son residentes en Córdoba, España, mientras que $20 \%$ viene ya sea de otra parte de España e inclusive de otro país, lo cual quiere decir que es más difícil para un estudiante extranjero vivir sin la familia y buscar otras fuentes de ingresos mientras realizan su estancia estudiantil en Córdoba.

Figura 18. Alojamiento

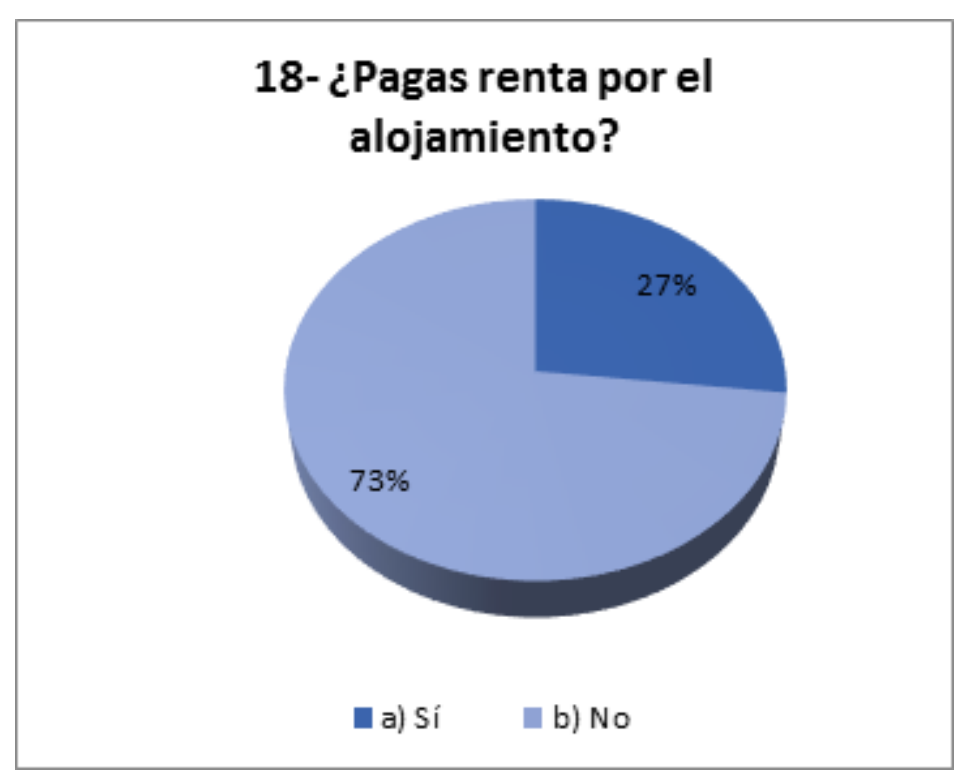

Fuente: Elaboración propia 


\section{Revista Iberoamericana para la Investigación y el Desarrollo Educativo ISSN $2007-7467$}

La figura 18 , muestra que $73 \%$ de los estudiantes no pagan alojamiento mientras realizan sus estudios universitarios, se aprecia que la mayoría vive con sus padres o tutores; por otro lado, $27 \%$ paga alojamiento para tener un lugar en donde pasar su trayectoria académica.

Figura 19. Pago de alojamiento por mes

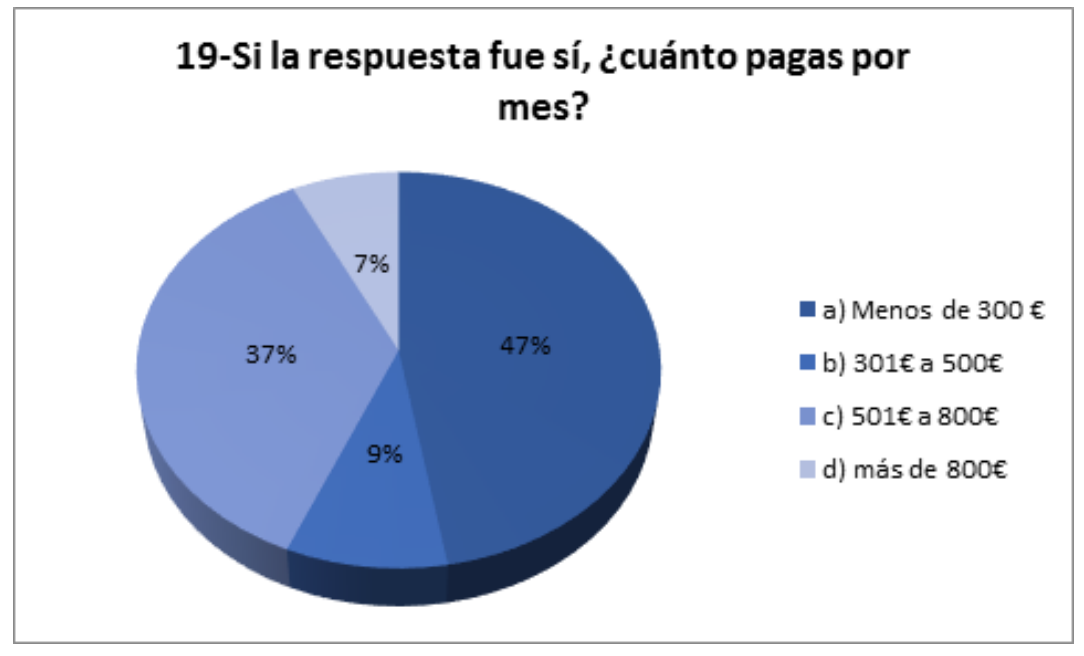

Fuente: Elaboración propia

En la figura 19 se observa que, de los 219 estudiantes encuestados, 59 de ellos tienen que pagar alojamiento, de los cuales $47 \%$ (28 estudiantes) paga menos de $€ 300$ al mes, $37 \%$ (22 estudiantes) paga de $€ 501$ a $€ 800$ para su alojamiento, $9 \%$ (5 estudiantes) paga de $€ 301$ a $€ 500$ y, por último, cuatro estudiantes pagan más de $€ 800$. 


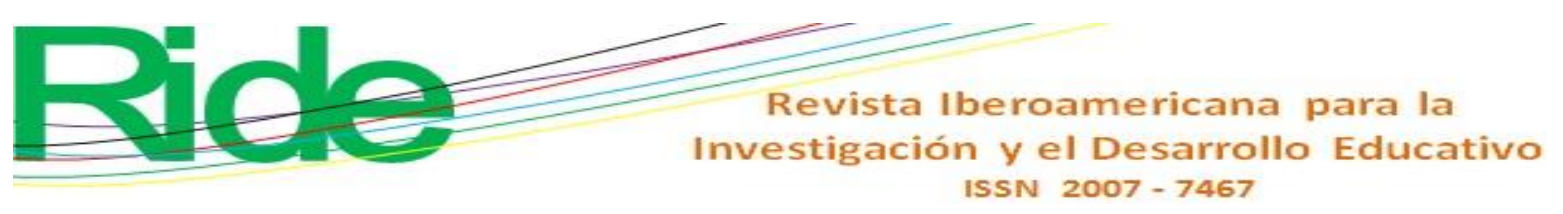

y España del área económico-administrativa; se reconoce que la tendencia financiera de los individuos es a ser previsora, ya que el interés es mantener una adecuada administración personal de sus finanzas. Es importante que desde el núcleo familiar se promueva una cultura financiera, debido a que conlleva a un proceso administrativo capaz de hacer rendir el dinero al máximo.

Las tomas de decisiones financieras son muy importantes, pues se puede o no tener éxito en estas, y para eso el tener una buena planeación sobre los ingresos y gastos a los que estamos expuestos diariamente, aun cuando sean gastos imprevistos. De ahí, también, lo trascendental de contar con ahorros, para salir adelante en objetivos y metas trazadas, de lo contrario se corre el riesgo de mermar en la economía.

Es valioso contar con una cultura en las finanzas, modificar los hábitos financieros, así como las formas de administración de los recursos monetarios para mejorar la calidad de vida. Sin duda es un reto enorme a nivel individual o empresarial el tema de la administración de los recursos, especialmente los económicos.

Fragmentos de este gran reto para los individuos son realizar un registro de los ingresos, elaborar un presupuesto por sencillo que sea, no gastar en cosas innecesarias, tener un hábito del ahorro, asesorarnos antes de tomar decisiones financieras y lograr la mayor asertividad posible en estas.

Los estudiantes de la Universidad Loyola Andalucía muestran una cultura financiera apropiada en su condición de hijo de familia, siguiendo los datos mayoritarios. El promedio de edad es de 20 años. Y si bien no muestran tener la capacidad de ahorro, tienen el hábito de este ejercicio. En esa línea, un área de oportunidad es la elaboración de un presupuesto de ingresos como de egresos, ya que, si logran tener el hábito de realizarlo, lo podrán aplicar tanto en su vida personal y como futuros profesionistas en su etapa productiva y aportar a la economía de su país.

Los individuos le damos valor a los aspectos sociales, los jóvenes no son la excepción, constantemente hacen comparaciones sociales y económicas. En este caso, la universidad en estudio es una institución privada, por lo que se puede suponer que todos tienen un nivel socioeconómico similar, pero no es así, ya que puede haber alumnos becados con diferentes estatus económico y social. No hay que dejar de tener en mente que la jerarquización en las sociedades actuales se basa tanto en la capacidad económica en sus ingresos como en el comportamiento social. 


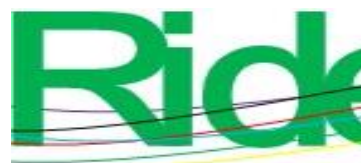

Revista Iberoamericana para la Investigación y el Desarrollo Educativo ISSN $2007-7467$

En esta investigación se refleja que la mayoría de los estudiantes tiene ingresos mensuales de $€ 51$ a $€ 100$, y en contraste con sus gastos semestrales, se observa que en la mayoría estos son mayores a $€ 800$, por lo que, se puede pensar, los ingresos mensuales de los estudiantes no necesariamente son para cubrir los gastos de colegiatura y que estos los realizan los padres, independientemente del gasto que les dan a sus hijos. Adicionalmente, $78 \%$ de los estudiantes son residentes de la ciudad de Córdoba y $70 \%$ no paga alojamiento, lo que indica que el comportamiento social en cuanto a sus orígenes sociales y económicos son estables, lo que permite a los alumnos tener conocimientos básicos y cultura financiera desde el núcleo familiar para planificar y administrar de una forma eficiente sus recursos económicos.

\section{Conclusiones}

Hablar de finanzas personales durante el trayecto académico de una licenciatura implica un proceso de administración financiera, llevar a cabo la planeación y estrategias que permitan una educación financiera estable y un proceso eficaz y eficiente que tenga la finalidad de obtener un hábito financiero durante dicha etapa estudiantil.

Las finanzas personales no difieren de un proceso administrativo organizacional, basta con tener claridad y honestidad en el historial, manejo y registro de gastos, deudas e inversiones para planear y diseñar estrategias, objetivos e implementar estas. Sistematizar los gastos personales y familiares conlleva un orden con la administración de los gastos que se realizan en la vida escolar y cotidiana.

Puede existir el fracaso en la planeación, hay factores que pueden presentarse y afectar la economía, tales como los impuestos, útiles escolares, matrículas, el tiempo, las emergencias, pero si se identifica la naturaleza del problema se puede iniciar el proceso y retomar los objetivos planteados para obtener resultados que finalmente beneficien a la economía familiar o personal.

En la presente investigación, de un total de 219 alumnos inscritos en la licenciatura en Administración, del ciclo escolar 2015-B en la Universidad de Loyola Andalucía, Córdoba, España, $79 \%$ tiene subsidiados sus gastos por sus padres, algún familiar o tutor. Esto muestra la dependencia familiar en la economía del estudiante. 


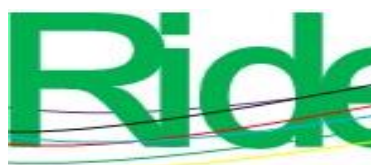

Revista Iberoamericana para la Investigación y el Desarrollo Educativo ISSN $2007-7467$

Los estudiantes, en su mayoría, reciben ingresos mensuales por más de €150; un menor porcentaje entre $€ 50$ a $€ 100$. Respecto de los gastos, indican que estos alcanzan más de $€ 800$ semestrales.

Por otro lado, $74 \%$ de los estudiantes tiene el hábito del ahorro, lo cual es muy bueno, ya que de ahí pueden partir para solventar gastos como transporte, diversión, comida y más; casi todos los estudiantes pueden tener acceso a este tipo de gastos sin problemas.

Además, $55 \%$ de los alumnos lleva control de ingresos y gastos. Esto indica que la cultura o educación financiera que se tiene desde la infancia en el núcleo familiar es bastante bueno, la cual les permite tener una visión amplia sobre sus ingresos, gastos, ahorro, endeudamiento y probablemente inversión, y la posibilidad de que este tipo de buenas prácticas financieras personales generen la optimización de sus recursos económicos.

Por consiguiente, $89 \%$ de los estudiantes no cuenta con deudas, ya que desde pequeños se les inculca una buena cultura financiera, son capaces de soportar con este tipo de problemas y demuestran eficiencia y eficacia a la hora de administrar su economía.

Ahora bien, $80 \%$ de los estudiantes reside en Córdoba; sus padres o tutores solventan los gastos de la casa y algunos de ellos hasta se ocupan de las matrículas escolares de sus hijos, lo cual permite que el estudiante solo requiera gastar en material escolar y así aumentar su poder adquisitivo.

Cabe mencionar que con estos resultados surgen inquietudes por saber a qué variables les dan más importancia en relación con sus gastos como estudiantes. Si bien la mayoría de ellos controlan, registran y manejan de una manera eficaz y eficiente sus finanzas personales, aun siendo estudiantes universitarios, hay pocos que todavía no adquieren una administración financiera personal, por lo que se aconseja buscar asesorías y con ellas mejorar su economía y que todos cuenten con una mejor calidad de vida.

Algunos de los alumnos expresan que no llevan algún control de sus finanzas personales, sobre todo en el ahorro, ya que eso les implica una labor y control periódicos para poder lograr sus metas previamente establecidas y tomar en cuenta no incrementar sus deudas.

Aunque los resultados que se arrojan en la presente investigación son favorables para los estudiantes, es recomendable considerar elaborar un presupuesto de ingresos y egresos para establecer metas u objetivos a corto, mediano y largo plazo, así como tener un control y conciencia de las deudas, para entonces ahorrar, poder invertir y tener un compromiso con 


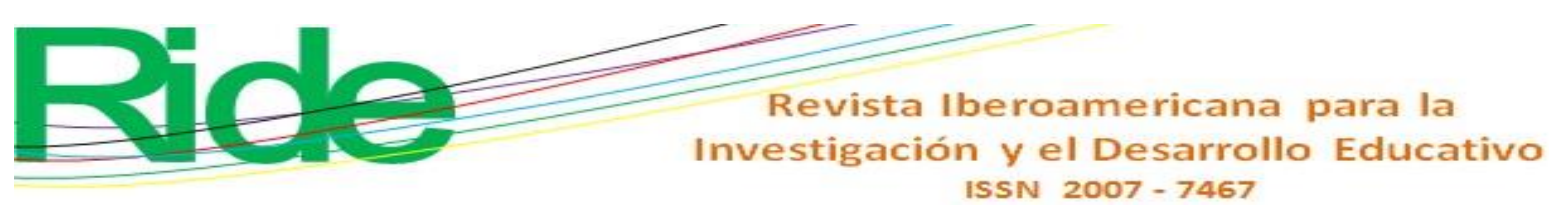

uno mismo. En el ámbito académico también puede ser motivo de estrés el tener problemas económicos, ya que se puede ver reflejado en el desaprovechamiento escolar.

\section{Referencias}

Comisión Nacional para la Protección y Defensa de los Usuarios de Servicios Financieros [Condusef]. (3 de junio de 2019). Un presupuesto para millennials. Proteja su Dinero. Recuperado de https://www.condusef.gob.mx/Revista/index.php/presupuestofamiliar/ingresos/1097-un-presupuesto-para-millennials.

Comisión Nacional para la Protección y Defensa de los Usuarios de Servicios Financieros [Condusef]. (30 de agosto de 2019). Reduce tu estrés financiero. ¡No tu dinero! Proteja su Dinero. Recuperado de https://www.condusef.gob.mx/Revista/PDFs/234/efi.pdf.

Correa, J. A., Ramírez, L. J. y Castaño, C. E. (2010). La importancia de la planeación financiera en la elaboración de los planes de negocio y su impacto en el desarrollo empresarial. Revista de la Facultad de Ciencias Económicas: Investigación y Reflexión, 43(1), 179-194. Recuperado de https://www.redalyc.org/comocitar.oa?id=90920479010.

Herrera, E. y Raccanello, K. (2014). Educación e inclusión financiera. Revista Latinoamericana de Estudios Educativos, 44(2), 119-141.

Marloreley. (5 de abril de 2016). Educación financiera temprana. Emprendices. Recuperado de https://www.emprendices.co/educacion-financiera-temprana/.

Morales, A. y Morales, J. A. (2010). Planeación financiera. Ciudad de México, México: Grupo Editorial Patria.

Núñez, L. (2013). Educación financiera. Retos, lecciones y planes. Ciudad de México, México: Instituto Mexicano de Contadores Públicos.

Ochoa, G. y Saldívar, R. (2012). Administración financiera correlacionada con las NIF (3. ${ }^{\text {a }}$ ed.). Ciudad de México, México: McGraw-Hill.

Olmedo, L. (2009). Las finanzas personales. Revista Escuela de Administración de Negocios, (65), 123-144.

Riquelme, M. (14 de julio de 2015). Funciones de la administración financiera. Web y Empresas. Recuperado de https://www.webyempresas.com/funciones-de-laadministracion-financiera/. 


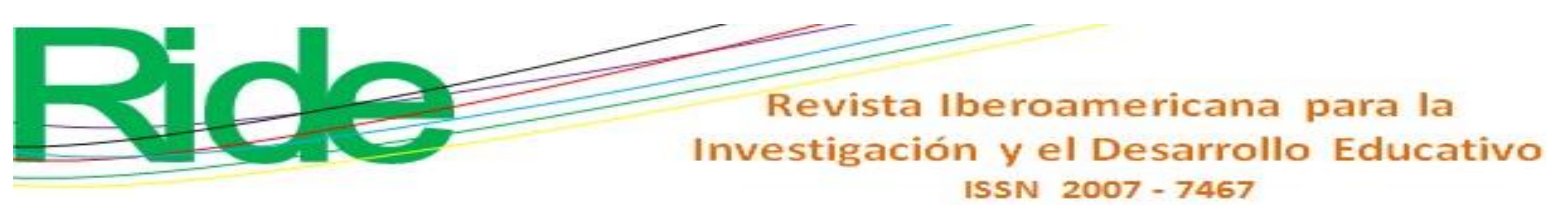

Tovar, A. (12 de mayo de 2016). Una administración financiera en familia. El Financiero. Recuperado de http://www.elfinanciero.com.mx/opinion/alberto-tovar/unaadministracion-financiera-en-familia.

Villagómez, F. A. (2014). El ahorro para el retiro. Una reflexión para México. El Trimestre Económico, 81(3), 549-576. 